\title{
Suction Elevator for Ear Surgery
}

\author{
R. Raman • Rahmat Omar
}

Received: 13 September 2009/Accepted: 31 January 2010/Published online: 9 February 2011

(C) Association of Otolaryngologists of India 2011

\begin{abstract}
An instrument has been designed to combine a suction and an elevator for use in ear surgery.
\end{abstract}

Keywords Suction - Elevator

\section{Introduction}

Middle ear surgery requires two hands. If one hand is used to hold an ear speculum, then the other hand is used in turns to do the surgery like elevation of flaps followed by suction. If an ear speculum holder is used, then the two hands are used to hold the suction in one and some other instrument in the other hand. If the function of the suction tip and elevator can be combined, one hand is left free for other instruments. A suction elevator has been developed which cuts the work down to one hand. A similar instrument is available for nasal surgery.

\section{Method}

The tip of a sucker (any type/any size) has been beveled and a bit flattened. The tip has been ground (using a lathe) to a shape of an elevator (duckbill), but taking care not to grind it to a knife point (Fig. 1). The tip is then polished. This is designed to suck while elevating a tympanomeatal flap, thus freeing one hand for holding an ear speculum (if the surgeon is used to that method) or freeing the other hand to hold any other instrument as required. This instrument is also useful if a drill is used in the other hand,

R. Raman $(\bowtie) \cdot$ R. Omar

Department of Otolaryngology, Faculty of Medicine,

University Malaya, 50603 Kuala Lumpur, Malaysia

e-mail: ramanr_99@yahoo.com

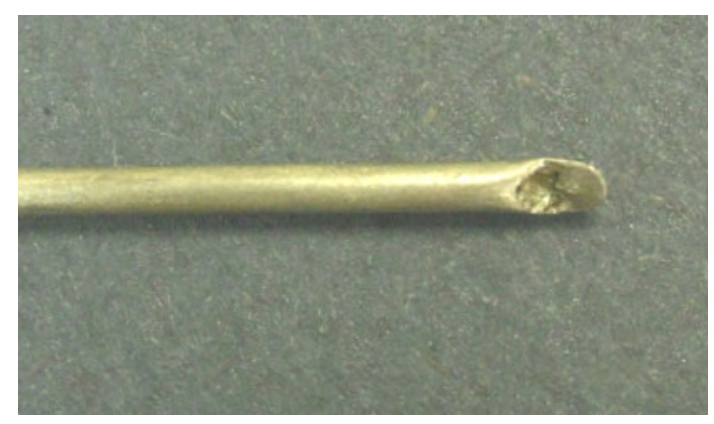

Fig. 1 Magnified view showing the tip of the sucker

to keep a tumor or cholesteatoma sac away, like a retractor, from the drill tip and apply suction at the same time.

The beveling and flattening can be done to the superior or inferior surface of the tip of the sucker depending on how the surgeon is used to holding the sucker.

\section{Comments}

The author uses this sucker for elevating canal flaps in myringoplasty/stapedectomy and mastoidectomies. It is beneficial in the raising of flaps in the external ear canal as mentioned above. In experienced hands tears are very rare just as in other elevators. Since the size of this design is for the skin flaps it has not been used for granulations and unhealthy polyps over the ossicles. The size designed is not meant for procedures on the footplate. But it is possible to design smaller sizes. The present size sucks bone dust. But it is usual/possible for any size suckers to get blocked by bone dust on and off.

\section{Summary}

A suction elevator has been designed for use in ear surgery. 